\title{
UNDERSTANDING COLLEGE STUDENTS' STUDY ABROAD MOTIVATIONS AND PREFERENCES
}

\author{
Swinder Janda, Kansas State University, USA \\ Bente Janda, Kansas State University, USA
}

\begin{abstract}
Current globalization trends and greater consumer mobility across nations has led to the world becoming cross-culturally integrated (Friedman, 2005; Hill, 2013). Businesses have increased global presence and employers are looking for candidates that in addition to core skills also possess cross-cultural skills (de Jong, Schnusenberg, and Goel, 2010). Thus higher education institutions are increasingly emphasizing global content including cultural perspectives and study abroad opportunities (American Council on Education, 2008; Relyea, Cocchiara, \& Stoddard, 2008). Inspite of all these developments, the vast majority of college students do not partake in study abroad opportunities before they graduate (Institute of International Education, 2012). In light of these observations, a two-step research design was adopted to understand student motivations, expectations, preferences, and outcomes associated with studying abroad. The first step involved a series of phenomenological interviews, while the second involved an online survey.
\end{abstract}

A fair number of recent research studies delve into this area and brief overview is provided here. Research suggests that the most effective way to gain cultural understanding and enhance language competency is by living in the country (Badstübner \& Ecke, 2009; Rexeisen \& Al-Khatib, 2009). Students who study abroad are typically motivated to broaden their horizons and obtain cultural enrichment (Sanchez, Fornerino, \& Zhang, 2006; Thissen, \& Ederveen, 2006). Other motivations include personal development and the desire to enhance friendships (Badstübner \& Ecke, 2009; Tomcar, Reid, \& Anderson, 2005).

In order to establish a thorough understanding of student study abroad perceptions, 15 phenomenological interviews were conducted with students who had recently studied abroad. Subsequent analysis of interview transcripts accompanied by readings of prior research uncovered numerous attitudes, motivations, preferences, and outcomes related to study abroad.

Insights from the above qualitative study were utilized to develop an online survey that contained questions pertaining to study abroad motivations (11 questions), attitudes (11 questions), and preferences (16 questions). The sampling frame comprised of 593 students enrolled at a major state university in the United States who had recently (within the last three months) expressed an interest in studying abroad. All questions utilized 7 point Likert type response formats. A total of 205 students completed the survey (68\% female and 32\% male). The SPSS software (Version 20) was employed to first conduct an exploratory factor analysis and then a K-means cluster analysis that yielded two clusters which are described below.

The "externally-motivated familiarity seekers" cluster represents $62 \%$ of the sample. Almost $75 \%$ of male respondents fall in this cluster, compared to $57 \%$ of female respondents. In their decision to study abroad, individuals in this cluster are particularly influenced by significant others, and are not particularly motivated to acquire foreign language skills or enhance marketability via study abroad. Further, this group strongly desires programs with English language instruction, and one that has U.S. professors and students. This group also prefers short duration (1-6 weeks) programs that are U.S. administered (faculty-led or foreign campus operated by home university). Individuals in this group also prefer living arrangements shared with other U.S. students. The "inherently motivated adventure seekers" cluster represents $38 \%$ of the sample. Only $25 \%$ of male respondents fall in this cluster, compared to $43 \%$ of female respondents. A desire to broaden their horizons and seek new adventure are particular motivations for this group. This group is also motivated to study abroad as a way of selfenhancement, often in the form of acquiring/enhancing foreign language skills. Moreover, this group strongly desires programs with a wide range of offerings, abundant travel opportunities, and few U.S. faculty and students. This group also prefers longer programs (one or two semesters) administered by a foreign university. Individuals in this group also prefer to live either with a host family or in off-campus shared living with other foreign students.

These findings have numerous marketing and administrative implications for institutions of higher education. A major implication is that there may be two broad segments of students based on their motivations and attitudes and what they are seeking in a study abroad program. The appropriate method to satisfy the needs of these two segments may be to offer different types of study abroad opportunities based on factors such as duration of time spent abroad, language of instruction, variety and type of travel possibilities within the program, and type of living arrangements while abroad. This can help increase student participation in study abroad programs and bring about a better student-program fit to ensure greater overall satisfaction among students, and to ultimately enhance the amount of value students get from such programs.

References available upon request. 